\title{
"CONECTADOS PELO ESPÍRITO": REDES PESSOAIS DE CONTATO E INFLUÊNCIA ENTRE LÍDERES EVANGÉLICOS AO SUL DA AMÉRICA LATINA
}

Daniel Alves ${ }^{1}$

Resumo: Esse trabalho tem por objetivo elucidar a importância de alguns líderes evangélicos (pastores, músicos e evangelistas com matizes semelhantes) como nós de redes de contato transnacionais entre Argentina, Brasil e Uruguai, a partir de entrevistas e diários de campo produzidos ao longo do ano de 2008 e 2009. Investimos num estudo qualitativo dessas redes, avaliando os aspectos que os separam em grupos se reconhecem, mas não atuam necessariamente em conjunto. Aqui descreveremos dois subgrupos de relaçóes no campo evangélico-pentecostal, suas ramificaçóes, seus centros de referência, seus usos dos meios de comunicação e as formas de construção da credibilidade pessoal. Escrever sobre a gênese e desenvolvimento dessas redes é uma forma, também, de contar a história dos movimentos pentecostais pós-denominacionais ao Sul da América Latina a partir da década de 1970.

Palavras-chave: Evangelismo, Pentecostalismo, América Latina, Transnacionalização, networks.

\begin{abstract}
In this work we aim to highlight the relevance of some evangelical leaders (pastors, musicians and evangelists with similar nuances) as nodes in transnational networks among Argentina, Brasil and Uruguay. We focus in a qualitative study about this network, appointing different actors that recognize themselves, but not necessarily act as a set. Here we will try to describe two subgroups in Evangelical-Pentecostal field, their centers of reference, their uses of medias and their construction of personal reliability. The origin and development of these networks is strictly related with the story of postdenominational movements in Southern Latin America since the seventies.
\end{abstract}

Keywords: Evangelism, Pentecostalism, Latin America, transnationalization, networks.

${ }^{1}$ Estudante de doutorado em Antropologia Social - PPGAS/UFRGS, bolsista de doutorado do Conselho Nacional de Desenvolvimento Científico e Tecnológico (CNPq-Brasil). Pesquisa com apoio de projeto do CNPq intitulado: "Transnacionalização, territorialização e representaçóes acerca do político e do religioso em Porto Alegre, Buenos Aires e Montevidéu", coordenado pelo prof. Dr. Ari Pedro Oro. Artigo apresentado originalmente como paper no GT 21 da XXVII Reunião da Associação Latino-Americana de Sociologia (ALAS), 31 de agosto a 4 de setembro de 2009.

Debates do NER, Porto Alegre, ano io, N. I6, P. 183-199, JUl./Dez. 2009 
Há pouco mais de um século, o pentecostalismo afirmou-se como um movimento de renovação cristã nos países do Norte, e logo a seguir se espalhou no Hemisfério Sul. Atualmente, com o aumento das trocas comerciais e culturais em nível global, certos ramos dessa linhagem religiosa derivada do protestantismo diversificaram suas formas de relacionamento interno. Estudamos nesse trabalho relações entre lideranças de organizaçóes pequenas e médias de até 30.000 membros, carismáticas e centralizadas, que se relacionam entre si como redes. Tais redes de contato e influência se constituem partilhando um imaginário teológico e político específico, e atravessam fronteiras nacionais com cada vez mais facilidade. Neste trabalho, nos perguntamos sobre como se formaram redes de contato e influência entre lideranças pentecostais e os deslocamentos transnacionais em três cidades na região do MERCOSUL: Buenos Aires (Argentina), Porto Alegre (Brasil) e, em menor grau, Montevidéu (Uruguai) ${ }^{2}$.

A existência de redes transnacionais globais no sentido Sul-Sul e Sul-Norte tem chamado a atenção de pesquisadores(as) das áreas de Ciências Humanas de muitos países, e não apenas no concernente ao tema "religiáo". Aqui, estaremos denominando transnacionais redes de relaçóes pessoa-a-pessoa que se criam e se mantêm entre países de forma mutli-local, e dentro das quais existe assimetria de poder e influência, mas sem uma referência a um centro, como na diáspora ${ }^{3}$. Inseridas na tensão contínua entre estrutura e agência que caracteriza a vida em sociedade, essas redes fomentam uma comunidade de pensamento que permite aos atores atuarem a partir de uma linguagem e de práticas rituais semelhantes em lugares diferentes. Questionamo-nos sobre as formas através das quais se efetuam esses contatos transnacionais entre agen-

${ }^{2}$ Escolhemos essas três cidades porque identificamos nelas redes que perpassam os campos pentecostais dos três países e, apesar de poderem ser mutuais, fomentam assimetrias hierárquicas de saber ritual e de influência que não são mediadas por uma instância central reguladora, mas por um sistema de reputação descentralizado e eficiente. Dada essa descrição, a internacionalização de denominaçóes como Igreja Universal do Reino de Deus (IURD) e Igreja Pentecostal Deus é Amor (IPDA), portanto, não será objeto de nossa investigação aqui.

${ }^{3}$ Conforme tipos-ideais construídos por Pries, 2005.

Debates do NER, Porto Alegre, Ano io, N. 16, P. I83-199, JUl./Dez. 2009 
tes religiosos, a linguagem comum que se instaura a partir deles, como essas relaçóes fazem sentido tendo em vista a história recente do pentecostalismo e as formas de capitalização simbólica dessas redes em vista do reforço das iniciativas desses pastores, músicos e evangelistas pentecostais.

Interessar-nos-á um aspecto ainda não ressaltado na bibliografia especializada: a existência dessas redes que envolvem denominaçóes de organização mais flexível quanto à mobilidade de suas lideranças no campo evangélico (Assembléia de Deus e Batistas, por exemplo) e congregaçóes de pequena e média escala. Isso faz, por exemplo, com que entre alguns pastores de Porto Alegre o modelo de culto de um evangelista ou a gerência de uma igreja de um pastor argentino sejam mais influentes que os conhecidos no Brasil.

Empregamos entrevistas semi-estruturadas com pastores e evangelistas das três cidades, e observação participante em rituais nos quais esses líderes atuavam, seja nas suas comunidades ou fora delas. Examinamos, a partir de material de entrevistas e diários de campo realizados no ano de 2008 e ao longo de $2009^{4}$, a importância de alguns líderes evangélicos e pentecostais como nós de uma rede 5 . Vamos fazer aqui uma caracterização dessas redes, para em outra oportunidade explorar seus aspectos conflitivos e consensuais. Isso equivale a considerar tanto os aspectos que fazem dessas redes uma unidade quanto outros que os separam em sub-redes que se reconhecem, mas não necessariamente atuam em conjunto.

\section{O MOVIMENTO DE DISCIPULADO NOS ANOS 70}

A primeira das redes de relaçôes que identificamos surgiu a partir da renovação carismática de setores evangélicos históricos, ao longo da década

\footnotetext{
${ }^{4}$ Até o presente momento, desde janeiro de 2008, fizemos viagens de campo a Buenos Aires e Montevidéu (30/09/2008 a 16/10/2008), além de acompanhar as igrejas de Porto Alegre que participam destas redes.

${ }^{5}$ A literatura sobre o uso do conceito de rede nas Ciências Sociais é extensa, e exigiu uma revisão bibliográfica já apresentada (Alves, 2008). Ver, fundamentalmente, Mitchell, 1974; Boissevain, 1979; Feldman-Bianco, 1987; e para trabalhos com abordagem semelhante à nossa, Pisani et al., 2007.
}

Debates do NeR, Porto Alegre, Ano io, N. I6, P. I83-I99, Jul./Dez. 2009 
de 70. Nessa época muitas pessoas descreviam-se insatisfeitas nas suas igrejas, porque já não tinham espaço para um culto mais intenso dentro delas, e encontraram como apoio uma estrutura que a primeira vista parecia mais flexível e aberta que a institucional. Ela foi gestada na Florida, no chamado grupo evangélico não-denominacional de Fort Lauderdale (Synan, 2005: 420). Tal estrutura desloca o foco do culto do templo para a casa, permitindo na intimidade dos lares o que, por seus defensores, foi visto como aprofundamento espiritual de pessoa a pessoa.

Essa estrutura foi calcada na idéia de discipulado. Uma pessoa tem seu processo de conversão acompanhado por alguém há mais tempo convertido. Este neófito, depois de um tempo, agregará em torno de si outro grupo pequeno de pessoas, e assim sucessivamente, formando uma espécie de pirâmide. Alguém que conhece o meio diria apressadamente que se trata do que hoje se chama igreja em células, mas aqui estamos falando do antecessor setentista desse tipo de organização. Simplesmente porque, nesse momento, a organização religiosa não se definia como instituição, mas como um movimento de pequenos grupos, com exigências de obediência aos novos adeptos, fechamento teológico-ideológico e abertura para a experimentação mística ${ }^{6}$.

$\mathrm{Na}$ Argentina, o primeiro grupo de pessoas que aderiram ao modelo de discipulado, em sua maior parte, era da igreja dos Irmãos Livres, e se reuniram pela primeira vez em 1967 (Canclini, 2004). Esse grupo se destacava não apenas pela forma de organização, mas também por suas práticas religiosas, tidas na época como "excessivas": segundo Canclini, as pessoas caíam no chão e riam-se sob a ação do Espírito Santo ${ }^{7}$. Neste primeiro grupo estava Jorge Himitian. Filho de pais armênios e evangélicos de Haifa, Himitian veio com sua família para a Argentina fugindo da guerra de 1948, aos sete anos. Atualmente é um dos principais responsáveis pela organização religiosa originada daquele momento, a Comunidad Cristiana, situada no

${ }^{6} \mathrm{O}$ que diferencia o discipulado das células é a intensidade do relacionamento entre discípulo e discipulador. O "pastoreamento" poderia chegar, segundo os acusadores do método, a uma relação de sujeição total.

7 É importante não perder de vista isso, pois o que era visto como "excesso" na década de 70 foi desenvolvido no avivamento na década seguinte, com muito mais respaldo no meio evangélico argentino.

Debates do NER, Porto Alegre, Ano io, N. 16, P. I83-199, JUl./Dez. 2009 
bairro de Flores, em Buenos Aires. A partir das considerações de Canclini (2004: 423), podemos afirmar que o surgimento dessa organização auxiliou a estabilização de um grupo e de uma linguagem comum, que tornou possível que esse grupo de pastores atualmente tenha reputação e voz no campo evangélico-pentecostal argentino.

Himitian tem contatos no Brasil em mais de uma dezena de cidades. Confirmamos a maior parte deles por informaçóes de sites de internet, porque quase todos eles estão relacionados a uma organização chamada Apostolic Fellowship International (AFI), que promove conferências anuais, sendo que a última foi ao final de setembro de 2008 em Santiago do Chile. Viaja a convite, geralmente com passagem paga pelos anfitriōes, mas poucos de seus hóspedes brasileiros são convidados por Himitian a vir para Buenos Aires. Entre esses contatos mais próximos, os de Porto Alegre são os mais numerosos, como Jan Gottfridsson, Erasmo Ungaretti e outros pertencentes ao grupo de discipulado de Moysés Moraes, o primeiro desse tipo em Porto Alegre, composto de pastores e evangelistas assim como o modelo da Comunidad Cristiana de Buenos Aires.

No grupo de Porto Alegre, nossa interlocução mais forte foi com Asaph Borba, músico de renome nos meios evangélico e pentecostal e com uma trajetória que começa, como é comum nesse meio, com um pertencimento a uma denominação histórica. Asaph Borba lançou 67 álbuns lançados, nas mais diversas línguas em seus 30 anos de carreira como músico profissional, e apoiou também mais de 350 gravaçóes de outros compositores e cantores, o que estendeu muito seu leque de relacionamentos, valorizados a todo o momento em entrevista. Tem estúdios pequenos em oito pontos do planeta, entre estes Cuba, Peru e Oriente Médio. A atual frente de divulgação do seu trabalho são países de maioria muçulmana.

Nos mesmos moldes que a experiência de Buenos Aires, a Comunidade Cristã de Porto Alegre integra atualmente mais de um milhar de pessoas que se reúnem semanalmente nas casas em pequenos grupos e numa reuniáo geral semanal no bairro Partenon, em Porto Alegre. Nas falas de Himitian e Asaph Borba, explicitam-se a mesma necessidade de "integridade" dos cristãos e se consolidam certas pautas de discussáo que são caras aos evan-

Debates do NER, Porto Alegre, ano io, N. I6, P. 183-199, JUl./Dez. 2009 
gélicos, no tópico "política e moral cristā" é considerada fundamental mas insuficiente, tendo que ser acompanhada pela postura correta diante dessas questóes que são apresentadas como sendo tão globais quanto à ação do Espírito Santo.

As comunidades cristãs de Porto Alegre, Buenos Aires e Santiago do Chile têm relaçóes estreitas entre si. Tanto Himitian vai a Porto Alegre pelo menos uma vez ao ano, quanto Asaph Borba tem uma base sólida de relacionamentos quando vai à Argentina, construída a partir da Comunidad, como é conhecida. Esses pontos de contato se estenderam também para o Paraguai, Bolívia e Uruguai.

\section{AVIVAMENTO ARGENTINO NOS ANOS 80 E SEUS DESDOBRAMENTOS, EM TRÊS TEMPOS}

Um evangelista de massas e um outro, de libertação, mudariam a cena evangélica argentina e teriam projeção mundial nos anos 80 . O primeiro deles foi Luis Palau, que a partir de uma viagem aos Estados Unidos nos anos 70, tornou-se conhecido no mundo inteiro. A inspiração inicial de Palau era o ministério do evangelista americano Billy Graham. Colomonos (2000) afirma que Graham foi um dos principais difusores da teologia política pentecostal ao mesmo tempo moderna em sua utilização das mídias e de cunho moral conservador, anteposta às posições do World Council of Churches (WCC)'.

${ }^{8}$ Os temas que podem ser levados aos púlpitos e aos cursos nesse meio são quase sempre os mesmos: aborto, homossexualismo e dissolução das unióes familiares.

9 As lideranças deste conselho de igrejas radicado em Genebra, comprometidas com um ecumenismo de viés tolerante e liberal, eram "acusados de todos os males, notadamente de serem responsáveis pela secularização e de estarem sujeitos às patologias do comunismo e do humanismo" (idem: 146, tradução do francês minha).

Debates do NER, Porto Alegre, ano io, N. 16, P. I83-199, JUl./Dez. 2009 
Luis Palau deve ao seu antecessor americano, essencialmente, essa tensão entre "teologia política" e "conciliação diplomática" com o mundo secular. Desde sua primeira campanha em 1978, na Bolívia, o espectro de comunicação social de Palau se ampliou. Tanto que hoje seus eventos de massa não são descritos como cruzadas ou cultos, mas como festivais. Essa mudança, segundo seu representante para a América Latina, o pastor batista Ruben Proietti, foi uma das mudanças decisivas de Luis Palau para a modernização da proposta evangelística de Graham. Diretamente, Palau fez parte da formação bíblica de uma das maiores lideranças atuais no campo evangélico-pentecostal argentino: Carlos Annacondia, nascido em 1944 na cidade de Quilmes.

Antes dos 35 anos, Annacondia era um próspero empresário do ramo metalúrgico em sua cidade natal, mas sua infância é descrita como tendo sido humilde. Ao final dos anos 70, Carlos Annacondia participava de um pequeno grupo carismático entre os Irmãos Livres em Quilmes. Destacouse e passou a ser convidado para pregar em outros lugares, inclusive em La Plata, capital da província de Buenos Aires. Foi nessa cidade, em 1984, que teve lugar o verdadeiro debut do evangelista como uma personalidade no meio evangélico nacional. Esse despertar de Annacondia é descrito por Rocky Grams no livro Asombrados en Argentina. Annacondia conseguiu unir-se a maior igreja da cidade naquele momento, do pastor Alberto Scataglini, e esse fato arrastou outras congregaçóes da cidade a apoiar Annacondia. Toda a seqüência de um culto desse tipo foi descrita em pormenores por Wynarczyk (1993), com uma atmosfera de festa popular, com cançôes, testemunhos e mensagens evangelísticas diretas, a que se seguia a "confrontação aos infernos", com pessoas na multidão manifestando possessões demoníacas. Hoje a equipe de evangelização de Annacondia, Mensaje de Salvación, organiza e dá apoio às suas viagens.

Em Porto Alegre, na década de 80, Isaías Figueiró era baterista na Comunidade Cristã em Porto Alegre, que mencionamos anteriormente, quando conheceu pessoalmente a Annacondia. Isaías é filho de um corretor de seguros, e desde a adolescência estava envolvido com a Comunidade Cristã de Porto Alegre. No final dos anos 80, distanciou-se da comunidade

Debates do NER, Porto Alegre, Ano io, N. I6, P. I83-I99, JUl./Dez. 2009 
e fez campanhas evangelísticas em Porto Alegre e arredores no estilo de Annacondia, com lonas de circo e práticas efusivas de libertação. Depois de fazer programas de rádio e de televisão nos inícios dos anos 90, em 1994, a partir da liderança de Isaías Figueiró e do pastor João de Oliveira Filho, formou-se uma congregação que alugou o antigo Cine Teatro Presidente. Por muitos anos, os dois pastores se tornaram uma referência na cena evangélica em Porto Alegre.

Em 2007, a Encontros de Fé (nome atual da congregação de Isaías) comprou a propriedade de uma transportadora, e transferiu a igreja para um espaço só dela. Atualmente, há 34 espaços espalhados em Porto Alegre e região metropolitana, e o próprio líder de Encontros de Fé estima que estejam na igreja cerca de 16.000 pessoas. A se fiar pelos números, seria a maior igreja autóctone de Porto Alegre. O pastor Isaías, por ora, não tem planos para expansão de sua igreja para além das fronteiras nacionais. Contudo, seu "ministério pessoal" como evangelista tem relaçôes fortes atualmente com Suécia e Moçambique, e existe um início de relacionamento com evangélicos italianos, este último estimulado pelo próprio Annacondia.

II

Em 1991, o casal de pastores da União das Assembléias de Deus Claudio e Betty Freidzon estava instalado no bairro de Belgrano, em Buenos Aires, com uma igreja de dois mil membros. A essa altura o casal era amigo de Annacondia, e como quase todos os pastores naqueles anos, adotaram seu estilo de pregação e prática ritual. Mas, nesse momento, os livros retrospectivos dos Freidzon (Espiritu Santo, tengo hambre de ti e Sorprendida por Dios, de Claudio e Betty, respectivamente) salientam certa inquietação da parte de Claudio, de ordem espiritual. Um amigo próximo recomendou a leitura do livro Bom dia, Espírito Santo, e logo a seguir Claudio Freidzon foi tentar conhecer o autor desse livro, Benny Hinn, nos Estados Unidos.

Segundo essas narrativas acerca do encontro com Benny Hinn, os efeitos da transformação em Claudio Freidzon logo se sentiram nos cultos. Uma

Debates do NER, Porto Alegre, Ano io, N. 16, P. I83-199, JUl./Dez. 2009 
sucessão de reunióes massivas se deu em seqüência, em lugares fechados de cada vez maior capacidade. A culminância desse processo foi em abril de 1992, no estádio do Vélez Sárzfield, com capacidade para 65.000 pessoas. Desde lá, os convites de viagens internacionais não pararam mais. A rotina semanal do casal, pelos relatos e pela agenda sempre a vista num sugestivo mapa clicável na internet, parece ser esta: durante a semana, viagens para conduzir cultos de avivamento; no fim de semana, condução da sua igreja, a Rey de Reyes, em Belgrano.

Desde 1997, os pastores Claudio e Betty Freidzon conduzem na igreja Rey de Reyes, juntamente com Annacondia e outro pastor chamado Sérgio Scataglini, uma "conferência de avivamento" ao final de setembro, chamado Breakthrough. O evento é dirigido para lideranças de ministérios de pequeno e médio porte, chegando a reunir pouco mais de 2.000 pessoas em cada edição, entre pastores, lideranças-chave e fiéis. Em 2008 contabilizamos cerca de quatrocentos brasileiros presentes, de várias cidades brasileiras. Breakthrough foi acompanhado diretamente por nós nos anos de 2008 e 2009, e nesses dois anos manteve um padrão de estrutura física e apoio aos estrangeiros, inclusive com traduçôes simultâneas das prédicas para o inglês e divulgação de certas partes dos cultos para outros países em tempo real, via Internet. A maior parte dos presentes via o evento dos Freidzon como um momento de formação e retiro espiritual, e pretendiam levar o conhecimento e a forma ritual (assentada no "evangelho de poder" de cunho pentecostal) para suas próprias congregaçõos no Brasil.

O casal porto-alegrense Silvio e Maria Ribeiro participou de um dos primeiros Breakthrough. Chegaram a morar em Belgrano, atuando como auxiliares na igreja dos Freidzon. Onze anos depois, em março de 2008, esse casal de pastores inaugurou a nova localização de seu ministério no Cine Teatro Presidente (outrora do pr. Isaías Figueiró) e deu início à campanha que trouxe o pastor Benny Hinn a Porto Alegre, em março de 2009. Para tanto, buscaram diversos apoios no meio evangélico da cidade.

A Cruzada de Fogo de Benny Hinn, para dar uma rápida descrição, foi conduzida em Porto Alegre durante os dias 13 e 14 de março de 2009, e teve uma organizaçáo impecável. Não contou com todos os apoios que esperava

Debates do NER, Porto Alegre, ano io, N. I6, P. I83-199, JUl./Dez. 2009 
no meio evangélico e com as presenças de autoridades (a governadora era esperada, veio o vice-prefeito da cidade), mas teve a participação importante da prefeitura, que deu suporte com o controle do tráfego e limpeza nos arredores do maior anfiteatro ao ar livre na cidade. $\mathrm{O}$ evento contou com mais de dez telóes de projeção ao vivo, um palco com capacidade para 2000 coristas, espaço para 5.000 pessoas sentadas e estandes de venda de artigos gospel. Os números de pessoas presentes divulgados são discutíveis; pelo que observamos podemos dizer que, no dia 14, havia de 60 a 80 mil pessoas assistindo à "cruzada de fogo". Apesar disso, a mídia televisada não deu destaque ao evento, e a impressa lançou poucas notas a respeito. Na maior parte, os 80 ônibus estimados pelas autoridades de tráfego que vieram para o evento eram pessoas de igrejas do interior do estado, e em menor parte, pessoas de outros estados da federação (Brasília, Curitiba São Paulo, Belo Horizonte e Manaus, por exemplo). Encontramos apenas uma caravana de país estrangeiro, de uma cidade fronteiriça perto de Aceguá, limite do RS com o Uruguai, fora pessoas isoladas que vieram de outros países.

III

Em outubro de 2006, o pastor Benny Hinn esteve promovendo um culto de milagres no estádio do Velez Sarzfield por dois dias, semelhante ao que houve em Porto Alegre em março de 2009. Na parte de fora do estádio, uma multidão ficou impedida de entrar pela polícia, inclusive um pastor de Porto Alegre chamado Josué Dilermando. Ele é atualmente pastor da igreja Maanaim, localizada hoje na zona norte de Porto Alegre, no bairro Rubem Berta. Foi a primeira de nossas entrevistas, de narrativa mais densa, e o momento em que nos demos conta que estávamos diante de um fenômeno que envolvia, também, igrejas de pequeno porte em bairros pobres. Saindo da Igreja Batista, Josué fundou a igreja Maanaim, que existe desde 2002 e hoje tem cerca de 100 membros. Atualmente, os contatos mais fortes de Josué com pessoas no exterior estão na Argentina, no Uruguai e em Santiago do Chile. Na Argentina, são o profeta José Luis Cuchelo e uma família de apóstolos judeus-cristãos.

Debates do NER, Porto Alegre, Ano io, N. 16, P. I83-199, JUl./Dez. 2009 
A igreja Maanaim foi o ponto de partida do qual Cuchelo estendeu seus contatos para dentro do RS. Uma entrevista com Cuchelo reforçou nossa impressão de que surgiu uma geração de líderes em Buenos Aires na década de 80 numa mesma igreja. Depois de anos trabalhando como músico e pastor em "Ondas de Amor e Paz" ${ }^{10}$, Cuchelo diz ter passado a ter uma visão de um "ministério profético", de revelaçôes. Saiu de "Ondas de Amor e Paz" mais ou menos na época em que estouraram certos escândalos como a separação do casal Giménez, e passou a ter um trabalho próprio que foi construindo no meio evangélico-pentecostal. Começou a trabalhar também no Brasil no ano 2000. No ano passado, quando o entrevistamos, ele estava na sua $16 .{ }^{\mathrm{a}}$ viagem, sempre transitando entre pequenas igrejas do sul do país.

Daniel Alves: Por quais cidades?

Cuchelo: Eu sempre começo aqui em Porto Alegre, depois vou a Criciúma, Camboriú, fui a São Paulo, Florianópolis, todos esses lugares, depois esses lugares mais vizinhos, Três Coroas, Teotônia, Camacuã, São Leopoldo.

Daniel Alves: E os pastores convidam? Como sabem?

Cuchelo: Porque são amigos entre eles, então um pastor que conhece o meu Ministério diz para aquele amigo, olha, vai, um amigo de um Ministério importante e bom, quer ir a sua igreja por duas noites, ele diz sim ou não, se ele quer, só tem que ter um coração aberto.

Outro caso de liderança egressa de "Ondas de Amor e Paz" é o de Jorge Márquez. Foi batista ao início de sua vida, na cidade de San Juan na Argentina, e depois ao viajar a Buenos Aires conheceu a igreja de Gimenez. Márquez afirmou em entrevista que, na época de "Ondas de Amor e Paz", disse ter passado por provaçóes grandes, chegou a ter que atender congregaçôes inteiras ainda como laico. Depois de algum tempo, em 1991, resolveu mudar-se para Montevidéu e abrir a sua igreja, denominada "Ministério

${ }^{10}$ Para mais informação sobre Ondas de Amor e Paz, de Hector Giménez, ver Spadafora, 1994, 2003.

Debates do NER, Porto Alegre, ano io, N. I6, P. 183-199, JUl./Dez. 2009 
Vida para las Naciones", reconhecida por ser uma das que crescem mais no Uruguai neste momento. A igreja do pastor Márquez transmite os cultos ao vivo pelo site na internet, além de ter espaços nas rádios nas faixas $\mathrm{AM} \mathrm{e}$ FM, e o canal Enlace TVN, que transmite em 33 empresas de canal a cabo no interior, o que lhes permite cobrir todo o território nacional. Ainda detém um sinal de satélite, com o qual transmitem a todas as Américas e à Espanha (Beltrán, et al., 2005: 35).

Sua sede está instalada na rua 8 de Outubro, próxima à estação rodoviária de Tres Cruces, na capital uruguaia, num antigo cinema chamado Liberty. Márquez afirmou que sua igreja não tem pretensões de expansão, apesar de manter uma filial na cidade natal San Juan (Argentina) e no Rio de Janeiro (Brasil), no bairro do Leme. Perguntei a ele como foi instalada essa extensão da igreja em terras brasileiras:

Márquez: Muito simples. Tinha um membro da igreja que queria abrir uma empresa no Rio de Janeiro. Com o tempo, evangelizou os empregados, e eles resolveram que tinham que ter uma igreja. Dos empregados passou-se as famílias, e agora estamos com uma igreja lá. Não temos pretensões de ter mais igrejas no exterior.

Daniel: Até porque hoje tem Internet...

Márquez: Sim, transmitimos direto daqui para muitas nações. As pessoas são curadas nos vendo pela internet. (Entrevista com Jorge Márquez, em 12 de outubro de 2008)

É importante destacar, por fim, o papel das mídias eletrônicas. Todas as igrejas que visitamos, mesmo as menores, procuram formas de divulgar seus cultos, seja por DVDs produzidos pelas igrejas, copiados e passados de mão em mão, seja via Internet. Assim como as lojas de CDs, DVDs e livros que sempre existem nos templos evangélicos, as câmeras digitais e ilhas de edição de imagens tem se tornado elementos corriqueiros nos cultos. Os líderes que entrevistamos costumam atribuir múltiplas funcionalidades a essas tecnologias. Uma delas, mencionada pelo pr. Jorge Márquez, é o uso das imagens como prática religiosa pentecostal. Se os livros e os textos dão

Debates do NER, Porto Alegre, Ano io, N. 16, P. I83-199, JUl./Dez. 2009 
testemunho de vidas edificantes ou de experiências extraordinárias, esses vídeos também, e mais. Os pastores sugerem que as pessoas podem fazer sua prática de louvor coletiva através esses vídeos impactantes, e que assisti-los pode resultar em milagres e curas. Esse tipo de utilização estimula que as pessoas copiem DVDs e troquem entre si. Em nossas mãos, eles se tornaram também objeto de troca na pesquisa. Entre as lideranças evangélicas entrevistadas, obviamente, ver os DVDs é também atualizar-se nos discursos e práticas que estão circulando nos principais pontos da rede.

Isso nos leva à funcionalidade de comunicação das tecnologias. É prática comum entrar em contato com um pastor e convidá-lo para vir pregar em uma igreja distante de sua residência em informaçóes de sites, desde que corroboradas pelos contatos mais próximos. As imagens que circulam, via mídia física ou streaming de vídeo, aumentam o alcance dessas lideranças para além das fronteiras nacionais, pois as estruturas para manter rádio e TV, ainda que consideradas importantes, são caras. Esses recursos de imagem e comunicação (entre os últimos, principalmente Skype e MSN) hoje são básicos para o entendimento da circulação transnacional entre as redes que atualmente estudamos.

\section{CONCLUSÃO}

Portanto, estamos diante de uma espécie de cena na qual os atores se conhecem em certa medida, e na qual os principais protagonistas não estão em Porto Alegre ou mesmo no Brasil, mas sim na Argentina. Hoje, podemos dizer que os principais nós dessa rede são: 1) Pr. Jorge Himitian; 2) Ev. Carlos Annacondia e 3) Pr. Claudio Freidzon. O caso do primeiro é distinto dos outros dois, porque o pr. Himitian e o grupo de pastores, evangelistas e músicos em torno das Comunidades Cristãs circulam entre si por viagens, ou se comunicam por internet, numa rede de apoio mútuo que tem certo grau de institucionalização. Os dois últimos parecem ter destaque no meio evangélico-pentecostal argentino, sendo reconhecidos por fazerem parte do establishment nesse cenário.

Observando o cenário transnacional que encontramos, seria adequado

Debates do NER, Porto Alegre, ANo io, N. I6, P. I83-I99, JUl./DeZ. 2009 
falar de um sistema de reputação, no qual o peso de um agente é proporcional ao número de contatos internacionais que explicita ter. Obviamente, há outros itens relevantes na construção da reputação nesse meio, como a afirmação constante de uma biografia pessoal e familiar condizente com a tradição cristã. Um efeito concreto da maneira com a qual esse sistema de reputação personalista age na comunicação é o fato de que, nas redes que estudamos, o nome do pastor ou do casal de pastores é sempre é mais lembrado que o ministério a qual eles pertencem.

Contudo, não se pode deixar de considerar as extensōes dessas redes para países fora do nosso escopo aqui. Os contatos entre as lideranças das Comunidades Cristãs, como vimos, são mediados principalmente pela Apostolic Fellowship International, que tem participação de líderes de países do mundo inteiro. Na segunda sub-rede, poderíamos mencionar que, na América de fala hispânica, o pastor argentino Omar Cabrera Jr. exerce uma influência considerável. Sua igreja Visión de Futuro tem ramificaçóes em toda a Argentina, e ele tem trazido para Buenos Aires pastores importantes como o casal Castellanos, de Bogotá, propagador principal do moderno modelo de igreja em células. Organizada por esse método, César Castellanos tem uma igreja de mais de 35.000 membros, que forneceu a base que garantiu a sua esposa, Alejandra Castellanos, um mandato como senadora da república na Colômbia. Isso sem mencionar as relaçóes que lideranças como Freidzon, Annacondia ou Cabrera mantém com igrejas evangélicas receptoras de população migrante hispânica nos Estados Unidos, tema a ser desenvolvido em textos posteriores.

\section{REFERÊNCIAS BIBLIOGRÁFICAS}

ALVES, Daniel. "A religião em rede: contribuições teóricas e metodológicas para um estudo sobre relaçōes transnacionais entre agentes religiosos pentecostais". Trabalho apresentado em: XXXII Encontro Anual da ANPOCS, Caxambu-MG, 27 a 31 de outubro, 2008. 
BELTRÁN, Andrés; CANTO, Soledad; FOSTIK, Ana \& ROJIDO, Emiliano. "El disciplinamiento en la conformación del ser religioso de la Iglesia Misión Vida para las Naciones”. In: FILARDO, Verónica (org.). Religiones alternativas en el Uruguay. Montevideo: Universidad de la República Oriental del Uruguay-Facultad de Ciencias Sociales, 2005, p. 27-48.

BOISSEVAIN, Jeremy. "Network Analysis: A reappraisal". Current Anthropology. Chicago, v. 20, nº. 2, 1979, p. 392-394.

CANCLINI, Arnoldo. 400 años de Protestantismo argentino: historia de la presencia evangelica en la Argentina. Buenos Aires: Fundación Argentina de Educación y Accion Comunitaria - Seminário Teológico FIET, 2004.

COLOMONOS, Ariel. Églises en réseaux: trajectoires politiques entre Europe et Amérique. Paris: Presses de Sciences Po, 2000.

FELDMAN-BIANCO, Bela (org.) Antropologia das sociedades contemporâneas. São Paulo: Global, 1987.

MITCHELL, J. Clyde. "Social networks". Annual Review of Anthropology, v. 3, 1974, p. 279-299.

PISANI, Francis; Saltalamacchia, Natalia; Tickner, Arlene B. \& Barnes, Nielan (orgs.) Redes transnacionales en la Cuenca de los Hurracanes: un aporté a los estudios interamericanos. México DF: Instituto Tecnológico Autónomo de México/Miguel Ângel Porrúa, 2007.

PRIES, Ludger. "Configurations of geographic and societal spaces: a sociological proposal between 'methodological nationalism' and the 'spaces of flows'”. Global Networks, v. 5, nº. 2, 2005, p. 167-190.

SPADAFORA, Ana María. "Creencias milenaristas e identidad religiosa pentecostal: el ministerio Ondas de Amor e Paz". In: FRIGERIO, Alejandro (org.). El Pentecostalismo en Argentina. Buenos Aires: Centro Editor de América Latina, 1994, p. 113-127. (Série Política Argentina, 459)

. "La Circularidad de la Experiencia de Campo: poder y desigualdad en la producción del conocimiento". Campos-Revista de Antropologia Social, v. 4, 2003, p. 135-153.

Debates do NER, Porto Alegre, ano io, N. I6, P. I83-199, JUl./Dez. 2009 
SYNAN, Vinson. "Corrientes de renovación al fin del siglo". In: SYNAN, Vinson (org.). El siglo del Espiritu Santo: cien años de renuevo pentecostal y carismatico. Buenos Aires: Peniel, 2005, p. 415-453.

WYNARCZYK, Hilário. "Carlos Annacondia: un estudio de caso en neopentecostalismo”. In: FRIGERIO, Alejandro (org.). Nuevos Movimientos Religiosos y Ciencias Sociales Vol. 2. Buenos Aires: Centro Editor de América Latina, 1993, p. 80-97. (Série Los fundamentos de las Ciencias del Hombre)

\section{REFERENNCIAS DE CAMPO}

ANNACONDIA, Carlos. Oime bien, Satanás! Nashville (EUA): Editorial Caribe, 1997.

FREIDZON, Betty. Sorprendida por Dios. Florida (EUA): Casa Creación, 2005a.

FREIDZON, Claudio. Espiritu Santo, tengo hambre de ti. Nashville (EUA): Editorial Caribe, 2005b.

GRAMS, Rocky. Asombrados en Argentina. Florida: Publicaciones Casa, 2007.

HIMITIAN, Jorge. Jesucristo el Señor. Buenos Aires: Logos,

HINN, Benny. Bom dia, Espírito Santo. São Paulo: Bompastor, 1995.

\section{PRINCIPAIS SITES CONSULTADOS}

Asaph Borba: <http://www.adorar.net>

Benny Hinn: <http://www.bennyhinn.org>

Carlos Annacondia: <http://www.carlosannacondia.org>

Claudio Freidzon: <http://www.claudiofreidzon.com>

Héctor Giménez: <http://www.hectorgimenez.com.ar>

Isaías Figueiró: <http://www.encontrosdefe.com.br> 
Jorge Márquez: <http://www.misionvida.org>

Josué Dilermando: <http://www.maanaimrs.com.br>

Luis Palau: <http://www.palau.org/>; <http://www.luispalau.net/>

Silvio Ribeiro: <http://www.avivamentoparaasnacoes.com.br/>

\section{OUTROS SITES IMPORTANTES}

Apostolic Fellowship International: <http://www.afint.org>

Cruzada de fogo de Benny Hinn em Porto Alegre, 2009: <http://www. cruzadabennyhinnbrasil.com.br>

Jornal El Puente, Argentina: <http://www.elpuenteonline.com> 
